\title{
Safety of esophagogastroduodenoscopy within 30 days of myocardial infarction: A retrospective cohort study from a Canadian tertiary centre
}

\author{
Fahad Al-Ebrahim MD*, Khurram J Khan MD*, Waleed Alhazzani MBBS, Ahmed Alnemer MBBS, \\ Abdullah Alzahrani MBBS, John Marshall MD MSc, David Armstrong MA MB BChir
}

F Al-Ebrahim, KJ Khan, W Alhazzani, et al. Safety of esophagogastroduodenoscopy within 30 days of myocardial infarction: A retrospective cohort study from a Canadian tertiary centre. Can J Gastroenterol 2012;26(3):151-154.

BACKGROUND: Patients who experience myocardial infarction (MI) are at risk of gastrointestinal (GI) bleeding complications. Endoscopic evaluation may lead to cardiopulmonary complications. Guidelines and studies regarding the safety of endoscopy in this population are limited. OBJECTIVE: To evaluate the safety of endoscopy in a retrospective cohort of post-MI patients at a Canadian tertiary centre.

METHODS: Using hospital diagnostic/procedure codes, the charts of patients meeting the inclusion criteria of having ST elevation MI or nonST elevation MI, and GI bleeding detected at endoscopy were reviewed. The information retrieved included demographics, medical history, medications, endoscopy details and cardiopulmonary/GI events.

RESULTS: A total of 121 patients experienced an MI and underwent endoscopy within 30 days. However, only 44 met the inclusion criteria and were reviewed. The mean age of the patients was 75 years, and $55 \%$ were female. The mean hemoglobin level was $86 \mathrm{~g} / \mathrm{L}$, and 38 of 44 patients required a transfusion. Comorbidities included hypertension $(82 \%)$, diabetes $(46 \%)$, heart failure $(55 \%)$, stroke $(21 \%)$, lung disease $(27 \%)$, previous MI (46\%), cardiac bypass surgery (30\%), history of GI bleed (25\%), history of ulcer $(18 \%)$ and ejection fraction $<50 \%(48 \%)$. The median number of days to endoscopy after MI was three. Complications included seven patients with acute coronary syndrome, one with arrhythmia, one with respiratory failure, one with aspiration pneumonia and two with perforation. Age, hemoglobin level or timing of endoscopy did not significantly predict a complication.

CONCLUSIONS: Patients with GI bleeding after MI often have comorbidities and are on antiplatelet agents. Endoscopy is a valuable tool in the diagnosis and management of bleeding complications, but must be weighed against the potential risk of other complications, which in the present study occurred in more than $25 \%$ of procedures.

Key Words: Acute myocardial infarction; Complication; Gastrointestinal endoscopy; Safety

$\mathrm{E}^{\mathrm{s}}$ ophagogastroduodenoscopy (EGD) is a safe, well tolerated and useful diagnostic and therapeutic procedure in the general population. Gastrointestinal (GI) bleeding is a common side effect of many antiplatelet/anticoagulation/thrombolysis drugs used in the management of ischemic heart disease, especially in the modern era of cardiology, in which patients are on multiple drugs that can increase the risk of bleeding (1-3). In specific high-risk patients, such as those with a recent myocardial infarction (MI), the safety of routine upper endoscopy is not well known but has been described as acceptable in several observational cohort studies, with complication rates ranging up to
La sécurité de l'œsophagogastroduodénoscopie dans les 30 jours suivant un infarctus du myocarde : une étude de cohorte rétrospective dans un centre canadien de soins tertiaires

HISTORIQUE : Les patients qui sont victimes d'un infarctus du myocarde (IM) sont vulnérables à des complications de saignement gastro-intestinal (GI). L'évaluation endoscopique peut provoquer des complications cardiorespiratoires. Les lignes directrices et les études relatives à la sécurité de l'endoscopie au sein de cette population sont limitées.

OBJECTIF : Évaluer la sécurité de l'endoscopie auprès d'une cohorte rétrospective de patients ayant subi un IM dans un centre canadien de soins tertiaires.

MÉTHODOLOGIE : Au moyen des codes de diagnostic ou d'intervention de l'hôpital, les chercheurs ont analysé les dossiers des patients respectant les critères d'inclusion d'IM avec ou sans élévation du segment ST et de saignement GI décelé à l'endoscopie. L'information saisie incluait les données démographiques, les antécédents médicaux, les médicaments, les détails de l'endoscopie et les événements cardiorespiratoires ou GI.

RÉSULTATS : Au total, 121 patients ont été victimes d'un IM et ont subi une endoscopie dans le 30 jours suivants. Cependant, seulement 44 respectaient les critères d'inclusion et ont fait l'objet d'une analyse. Les patients, dont $55 \%$ étaient des femmes, avaient un âge moyen de 75 ans. Ils avaient un taux d'hémoglobine moyen de $86 \mathrm{~g} / \mathrm{L}$, et 38 des 44 patients ont dû subir une transfusion. Les comorbidités incluaient l'hypertension (82\%), le diabète (46\%), l'insuffisance cardiaque (55\%), un accident vasculaire cérébral (21\%), une maladie pulmonaire ( $27 \%$ ), un IM passé (46 \%), un pontage aortocoronarien (30\%), des antécédents de saignement GI (25\%), des antécédents d'ulcère (18\%) et une fraction d'éjection inférieure à $50 \%$ (48 \%). Après un IM, on constatait un nombre médian de trois jours avant l'endoscopie. Les complications incluaient sept patients ayant un syndrome coronarien aigu, un patient ayant une arythmie, un ayant une insuffisance respiratoire, un ayant une pneumonie d'aspiration et deux ayant une perforation. Lâge, le taux d'hémoglobine ou le moment de l'endoscopie ne permettaient pas de prédire une complication de manière significative.

CONCLUSIONS : Les patients ayant un saignement GI après un IM présentent souvent des comorbidités et prennent des antiplaquettaires. L'endoscopie est un outil précieux pour diagnostiquer et prendre en charge les complications de saignement, mais il faut en soupeser l'utilité par rapport au risque potentiel d'autres complications, qui, dans la présente étude, se produisaient dans plus de $25 \%$ des interventions.

7.5\% (4-7). In other studies, there are significant differences in mortality in acute coronary syndrome (ACS) patients who experience GI bleeding, suggesting they are a higher-risk population $(8,9)$.

EGD is an important diagnostic tool in up to $85 \%$ of patients who experience post-MI bleeding (6); is generally safe in high-risk patients and can shorten hospitalization (10). Early endoscopy $(<24 \mathrm{~h})$ is recommended in most patients, and risk stratification is achieved with measures such as the Blatchford or Rockall score (11-13). However, post-MI patients may also be more susceptible to cardiopulmonary complications including recurrent myocardial ischemia, hypoxia,

St Joseph's Healthcare, McMaster University, Hamilton, Ontario. *Co-first authors

Correspondence: Dr Khurram Khan, St Joseph's Healthcare, Room H424, 50 Charlton Avenue East, Hamilton, Ontario L8N 4A6.

Telephone 905-521-2100 ext 76768, fax 905-521-4958, e-mail khankj@mcmaster.ca

Received for publication May 18, 2011. Accepted July 9, 2011 
TABLE 1

\section{Demographic and clinical characteristics of 44} postmyocardial infarction (MI) patients

\begin{tabular}{lc}
\hline Characteristic & \\
\hline Age, years, mean \pm SD & $73.5 \pm 10.5$ \\
Male sex, $\mathrm{n}(\%)$ & $20(45.5)$ \\
Hemoglobin, g/L, mean \pm SD & $86 \pm 27.8$ \\
Median days to endoscopy after MI (range) & $3(0-31)$ \\
Rockall score, median (interquartile range) & $5(5-7)$ \\
Comorbidities, n (\%) & \\
Hypertension & $36(81.8)$ \\
Diabetes & $20(45.5)$ \\
Congestive heart failure & $24(54.5)$ \\
Stroke & $9(20.5)$ \\
Lung disease & $12(27.3)$ \\
Coagulopathy & $3(6.8)$ \\
Previous MI & $20(45.5)$ \\
Previous cardiac bypass surgery & $13(30)$ \\
Previous gastrointestinal bleed & $11(25)$ \\
Previous peptic ulcer disease & $8(18)$ \\
Ejection fraction <50\% & $21(48)$ \\
Antiplatelets/NSAIDs taken within 7 days, $\mathrm{n}(\%)$ & \\
Acetylsalicylic acid & $27(61.5)$ \\
Clopidogrel & $8(18)$ \\
NSAIDs & $3(6.8)$ \\
\hline
\end{tabular}

NSAIDS Nonsteroidal anti-inflammatory drugs

\section{TABLE 2}

\section{Endoscopy indications and transfusion requirements}

\begin{tabular}{lc}
\hline Indication for endoscopy & $8(18)$ \\
Hematemesis & $10(22.7)$ \\
Coffee ground emesis & $24(54.5)$ \\
Melena & $4(9.1)$ \\
Bright red blood per rectum & \\
Transfusion requirements & $38(86)$ \\
Required blood transfusion & $4.6 \pm 3.5$ \\
Units of blood, mean \pm SD
\end{tabular}

Data presented as $n$ (\%) unless otherwise indicated

anxiety or discomfort, hypotension and aspiration due to sedation or the procedure itself. Some earlier studies demonstrated a risk of cardiopulmonary complications that is highest immediately after a myocardial event, and more common in sicker patients based on acute physiology and chronic health evaluation criteria (5-7).

The present cohort study was designed to capture the cardiopulmonary safety concerns around post-MI endoscopy, and to evaluate specific predictors of complications such as age, hemoglobin ( $\mathrm{Hgb})$ level and time from MI to endoscopy.

\section{METHODS}

The study was conducted at the Hamilton Health Sciences Hospitals (McMaster University Medical Centre, Hamilton General Hospital, and Henderson Hospital) in Hamilton, Ontario, and approved by the hospitals' research ethics boards. Patients admitted between 2003 and 2006 were identified retrospectively by computerized analysis of primary or secondary medical disease codes (International Classification of Diseases - 9th revision) for myocardial infarction and upper GI bleeding, and by procedure codes for EGD.

Inclusion criteria for the study were as follows: adult patients (age $>18$ years) with ACS (including ST elevation myocardial infarction [STEMI] and non-STEMI [NSTEMI] with documented elevation in troponin level) who underwent EGD for suspected GI bleeding within 30 days of an incident acute coronary event. Reasons for exclusion included troponin elevation for renal failure, upper GI bleed before MI, EGD before MI and/or misdiagnosis.
Individual patient charts that met the inclusion criteria were carefully reviewed, and data relevant to the study were extracted using a standardized data extraction form. This included baseline demographics of age, sex, medical history (hypertension, diabetes, congestive heart failure, stroke, chronic lung disease, bleeding disorder, renal failure, MI, GI bleeding or peptic ulcer disease), medication use before endoscopy (eg, acetylsalicylic acid, clopidogrel, heparin, warfarin, beta-blockers, nonsteroidal anti-inflammatory drugs, proton pump inhibitors), details surrounding the endoscopy (indication, medications, complications, vital signs, diagnosis) and any adverse cardiopulmonary outcomes including significant cardiac arrhythmias, congestive heart failure, respiratory failure, hypoxemia (oxygen saturation $<85 \%$ ), recurrent ACS, significant hypotension (mean arterial pressure $<70 \mathrm{mmHg}$, or in patients hypotensive at baseline - a drop in mean arterial pressure of $15 \%$ ) or hypertension, aspiration pneumonia and death.

Statistical analysis was performed using SPSS version 19 (IBM Corporation, USA). Categorical variables were analyzed using Fisher's exact test or the $\chi^{2}$ test. Continuous variables (mean $\pm \mathrm{SD}$ ) were analyzed using the Student's $t$ test or the Mann-Whitney test, as appropriate. ORs and $95 \%$ CIs were calculated from stepwise logistic regression analysis of the a priori predictors for cardiopulmonary complications.

\section{RESULTS}

During the four-year study period, a total of 121 patient charts describing a diagnosis of an MI with an EGD within 30 days were reviewed. However, after careful analysis, only 44 patients met the inclusion criteria.

The mean age of study patients was 73.5 years, and $55 \%$ were female. Most patients had at least one comorbidity, and one-quarter experienced a previous GI bleed. The median Rockall score was 5 . Almost $80 \%$ of the patients were taking an antiplatelet agent at the time of the bleed (Table 1). The average Hgb level was $86 \mathrm{~g} / \mathrm{L}$ at the time of EGD, and $86 \%$ of patients required a transfusion (Table 2). The most common indication for EGD was melena in $55 \%$ of cases (Table 2). More than $50 \%$ of patients underwent EGD within the first three days post-MI. The median number of days to endoscopy after MI was three with a range of zero to 31 days.

EGD was diagnostic for the cause of bleeding; the most common diagnoses were duodenal or gastric ulcer, erosions, varices and esophageal ulcers. Complications occurred in 12 (27.5\%) patients, with recurrent ACS being the most common in seven of the 12 (Table 3). Other complications included arrhythmia, respiratory failure, aspiration pneumonia and perforation. Logistic regression was used to determine whether age, Hgb level or days since MI (more than three days or less than three days) were important in predicting which patients would experience a complication. None of the factors were significant (age $[\mathrm{P}=0.41]$; Hgb level $[\mathrm{P}=0.65]$; or days since $\mathrm{MI}[\mathrm{P}=0.81])$.

\section{DISCUSSION}

The present study showed that patients who required an EGD after a recent ( $<30$ days) MI demonstrated higher rates of serious complications $(27.5 \%)$ than previously reported in similar retrospective cohort studies (4-7). However, there were no deaths, whereas other studies reported mortalities in this population $(8,9)$. The reason for the increased complication rate is unclear; most were recurrent ACS possibly due to antiplatelet medications being discontinued for active bleeding. Other explanations may relate directly to endoscopy because some experiments have shown that gastric insufflation and vagally mediated reflexes could trigger ischemia (14-16).

According to some studies, the highest risk of complication is in the first $24 \mathrm{~h}$ post-MI (7); however, in our cohort, we divided the patients into those who underwent EGD within three days and after three days of an MI. The logistic regression model adjusted for $\mathrm{Hgb}$ level and age did not show a significant impact of the timing of the EGD. 
Another explanation for the higher complication rate is that patients in the study had many comorbidities and up to $80 \%$ were treated with an antiplatelet agent. The baseline Hgb level was also quite low $(86 \mathrm{~g} / \mathrm{L})$, and most patients $(86 \%)$ required transfusion. The average Rockall score was 5, but was skewed toward the higher values, which suggest there was at least an intermediate risk of rebleeding following endoscopy. EGD proved to be an important diagnostic tool in risk stratification for upper GI bleeding because most patients had evidence of GI pathology. Patients not selected for endoscopy were likely even sicker, but as newer endoscopic hemostasis techniques are more widely used, the modern endoscopist is likely better equipped and, hence, possibly more willing to perform EGD in patients with severe comorbidities. International consensus recommendations on the management of patients with nonvariceal upper GI bleeding recently published by Barkun et al (13) suggest that EGD should not be deferred for more than $24 \mathrm{~h}$ except in certain high-risk patients, such as those with ACS or a perforation; however, no specific time frame is mentioned. The utility of deferring EGD is still controversial in patients with a concomitant ACS and GI bleed. A retrospective study by Lin et al (10) determined that in $43 \%$ of cases, an urgent EGD influenced the timing of cardiac catheterization. Yachimski et al (17) performed a decision analysis in which they proposed that an urgent EGD before cardiac catheterization was safer in patients with an ACS and overt GI bleeding.

\section{Study limitations}

The present study was retrospective in nature and, thus, had some bias in its design. There is selective reporting of only patients who underwent EGD for GI bleeding within 30 days of an MI, but no collection of data on patients with a GI bleed who did not undergo endoscopy. Our study focused on the safety of EGD and peri-MI complications, and investigated an a priori question of whether the timing of endoscopy is related to complications (7). Data were collected, but specific criteria assessing the severity of the bleed and timing of bleeding symptoms to endoscopy were not assessed. Outcomes were subjectively assessed based on documentation in the clinical record. Definitive conclusions could not be drawn using a logistic regression model because of the small sample size.

\section{REFERENCES}

1. Choudari CP, Rajgopal C, Palmer KR. Acute gastrointestinal haemorrhage in anticoagulated patients: Diagnoses and response to endoscopic treatment. Gut 1994;35:464-6.

2. Schomig A, Kastrati A, Dirschinger J, et al. Coronary stenting plus platelet glycoprotein IIb/IIIa blockade compared with tissue plasminogen activator in acute myocardial infarction. N Engl J Med 2000;343:385-91.

3. Van Es RF, Jonker JJ,Verheught FW, et al. Aspirin and coumadin after acute coronary syndromes (the ASPECT-2 Study): A randomised controlled trial. Lancet 2002:360:109-13.

4. Lee JG, Krucoff MW, Brazer SR. Periprocedural myocardial ischemia in patients with severe symptomatic coronary artery disease undergoing endoscopy: Prevalence and risk factors. Am J Med 1995;99:270-5.

5. Cappell MS. The safety and clinical utility of esophagogastroduodenoscopy for acute gastrointestinal bleeding after myocardial infarction: A six-year study of 42 endoscopies in 34 consecutive patients at two university teaching hospitals. Am J Gastroenterol 1993;88:344-50.

6. Cappell MS, Iacovone FM Jr. Safety and efficacy of esophagogastroduodenoscopy after myocardial infarction. Am J Med 1999;106:29-35.

7. Spier BJ, Said A, Moncher K, Pfau PR. Safety of endoscopy after myocardial infarction based on cardiovascular risk categories: A retrospective analysis of 135 patients at a tertiary referral medical center. J Clin Gastroenterol 2007;41:462-7.

8. Al-Mallah M, Bazari RN, Jankowski M, Hudson MP. Predictors and outcomes associated with gastrointestinal bleeding in patients with acute coronary syndromes. J Thromb Thrombolysis 2007;23:51-5.

\section{TABLE 3}

Endoscopy findings and postendoscopy complications

\begin{tabular}{lc}
\hline Endoscopy findings, $\mathrm{n}$ & \\
Duodenal ulcer & 15 \\
Gastric ulcer & 14 \\
Erosions & 8 \\
Varices & 6 \\
Esophageal ulcer & 5 \\
Esophagitis & 2 \\
Pyloric ulcer & 1 \\
Esophageal cancer & 1 \\
Candidiasis & 1 \\
Complications, n (\%) & \\
Any & $12(27.5)$ \\
Acute coronary syndrome & $7(16)$ \\
Arrhythmia & $1(2.3)$ \\
Respiratory failure & $1(2.3)$ \\
Aspiration pneumonia & $1(2.3)$ \\
Perforation & $2(5.1)$ \\
\hline
\end{tabular}

\section{Clinical implications}

The current study demonstrated that EGD was associated with a substantial risk of complication post-MI, which may have been underestimated in previous studies. Reasons for the higher rates of complications are not clear. The patients may be sicker, and/or the more aggressive use of anticoagulation/antiplatelet agents for an older population in the modern era of cardiology is a plausible explanation. The decision to perform EGD in a sick patient will always be difficult, but the goal of reducing bleeding and hypoperfusion by endoscopically identifying and treating a bleeding lesion must remain paramount. Several other studies similarly conclude that endoscopic evaluation using flexible sigmoidoscopy, colonoscopy, endoscopic retrograde cholangiopancreatography and even percutaneous endoscopic gastrostomy tube placement, is safe in patients post-MI (18-21). When necessary, alternative options, such as wireless capsule endoscopy, may replace many indications for diagnostic EGD because of higher sensitivity, less procedural invasiveness and greater patient safety (22).

9. Nikolsky E, Stone GW, Kirtane AJ, et. al. Gastrointestinal bleeding in patients with acute coronary syndromes: Incidence, predictors, and clinical implications: analysis from the ACUITY (Acute Catheterization and Urgent Intervention Triage Strategy) trial. J Am Coll Cardiol 2009;54:1293-302.

10. Lin HJ, Wang K, Perng CL, et al. Early or delayed endoscopy for patients with peptic ulcer bleeding. A prospective randomized study. J Clin Gastroenterol 1996;22:267-71.

11. Blatchford O, Murray WR, Blatchford M. A risk score to predict need for treatment for upper-gastrointestinal haemorrhage. Lancet 2000;356:1318-21.

12. Rockall TA, Logan RF, Devlin HB, Northeld TC. Risk assessment after acute upper gastrointestinal haemorrhage. Gut 1996;38:316-21.

13. Barkun AN, Bardou M, Kuipers EJ, et al; International Consensus Upper Gastrointestinal Bleeding Conference Group. International consensus recommendations on the management of patients with nonvariceal upper gastrointestinal bleeding. Ann Intern Med 2010;152:101-13.

14. Gilbert NC, LeRoy GV, Fenn GK. The effect of distention of abdominal viscera on the blood flow in the circumflex branch of the left coronary artery of the dog. Am Heart J 1940;20:519-24.

15. Cunningham ET Jr, Ravich WJ, Jones B, Donner MW. Vagal reflexes referred from the upper aerodigestive tract: An infrequently recognized cause of common cardiorespiratory responses. Ann Intern Med 1992;116:575-82.

16. Palmer ED. The abnormal upper gastrointestinal vagovagal reflexes that affect the heart. Am J Gastroenterol 1976;66:513-22.

17. Yachimski P, Hur C. Upper endoscopy in patients with acute myocardial infarction and upper gastrointestinal bleeding: Results of a decision analysis. Dig Dis Sci 2009;54:701-11. 
18. Cappell MS. Endoscopic retrograde cholangiopancreatography with endoscopic sphincterotomy for symptomatic choledocholithiasis after myocardial infarction. Am J Gastroenterol 1996;91:1827-31.

19. Cappell MS. Gastrointestinal bleeding associated with myocardial infarction. Gastroenterol Clin North Am 2000;29:423-44.

20. Cappell MS. The safety and clinical utility of flexible sigmoidoscopy and colonoscopy for gastrointestinal bleeding after myocardial infarction: A six-year study of 18 consecutive lower endoscopies at two university teaching hospitals. Dig Dis Sci 1994;39:473-80.
21. Cappell MS, Iacovone FM Jr. The safety and efficacy of percutaneous endoscopic gastrostomy after recent myocardial infarction: A study of 28 patients and 40 controls at four university teaching hospitals. Am J Gastroenterol 1996;91:1599-603.

22. Saurin JC, Delvaux M, Gaudin JL, et al. Diagnostic value of endoscopic capsule in patients with obscure digestive bleeding: Blinded comparison with video push-enteroscopy. Endoscopy 2003;35:576-84. 


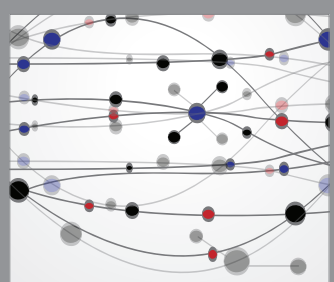

The Scientific World Journal
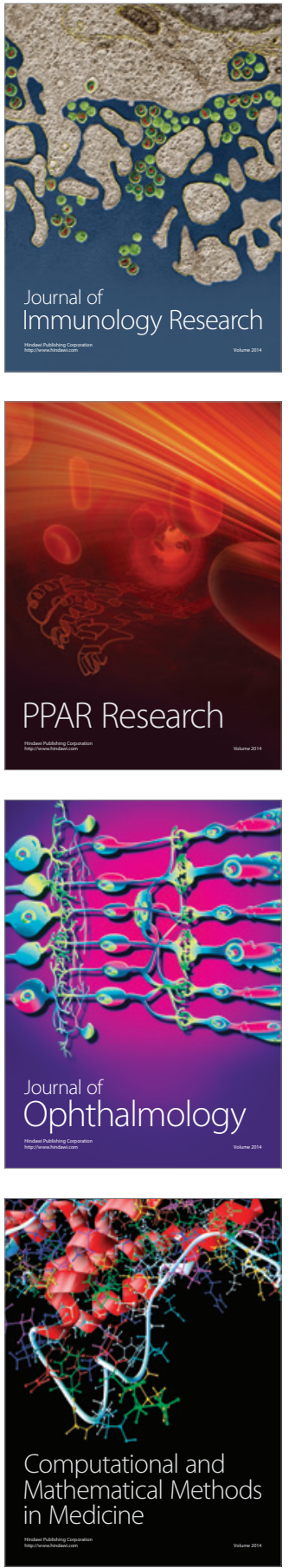

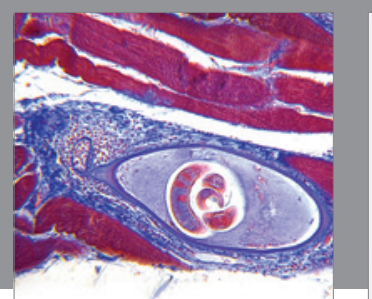

Gastroenterology Research and Practice

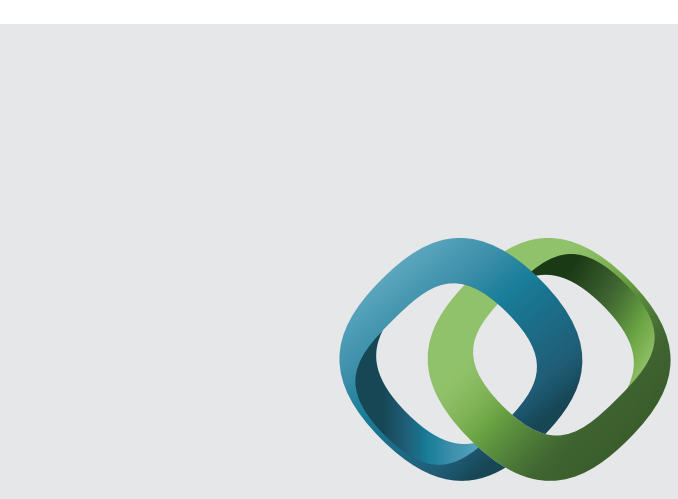

\section{Hindawi}

Submit your manuscripts at

http://www.hindawi.com
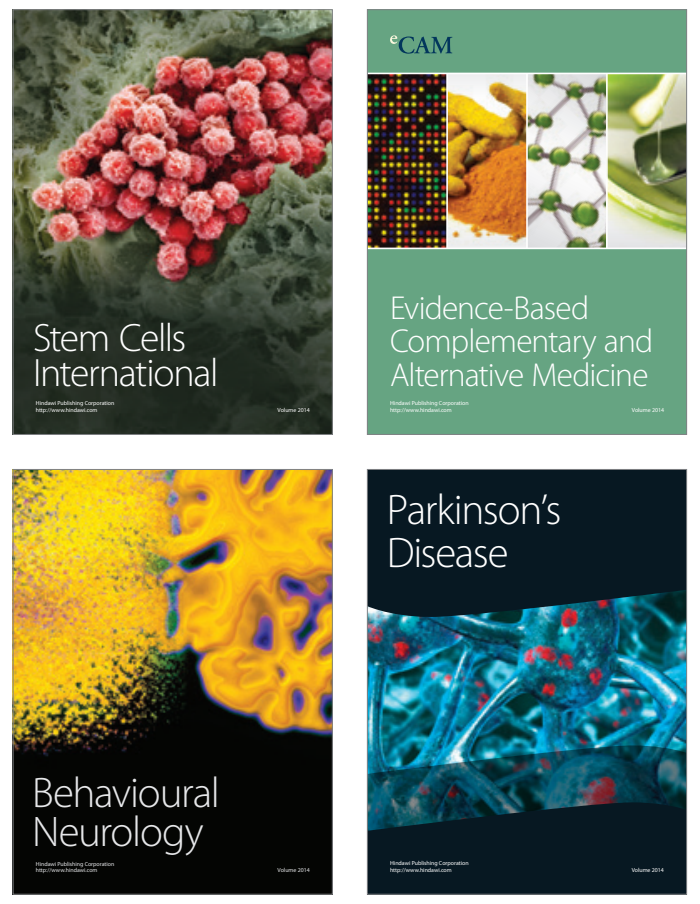
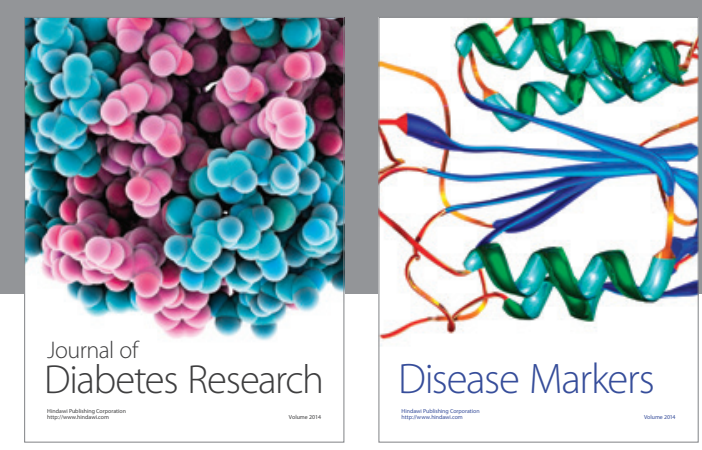

Disease Markers
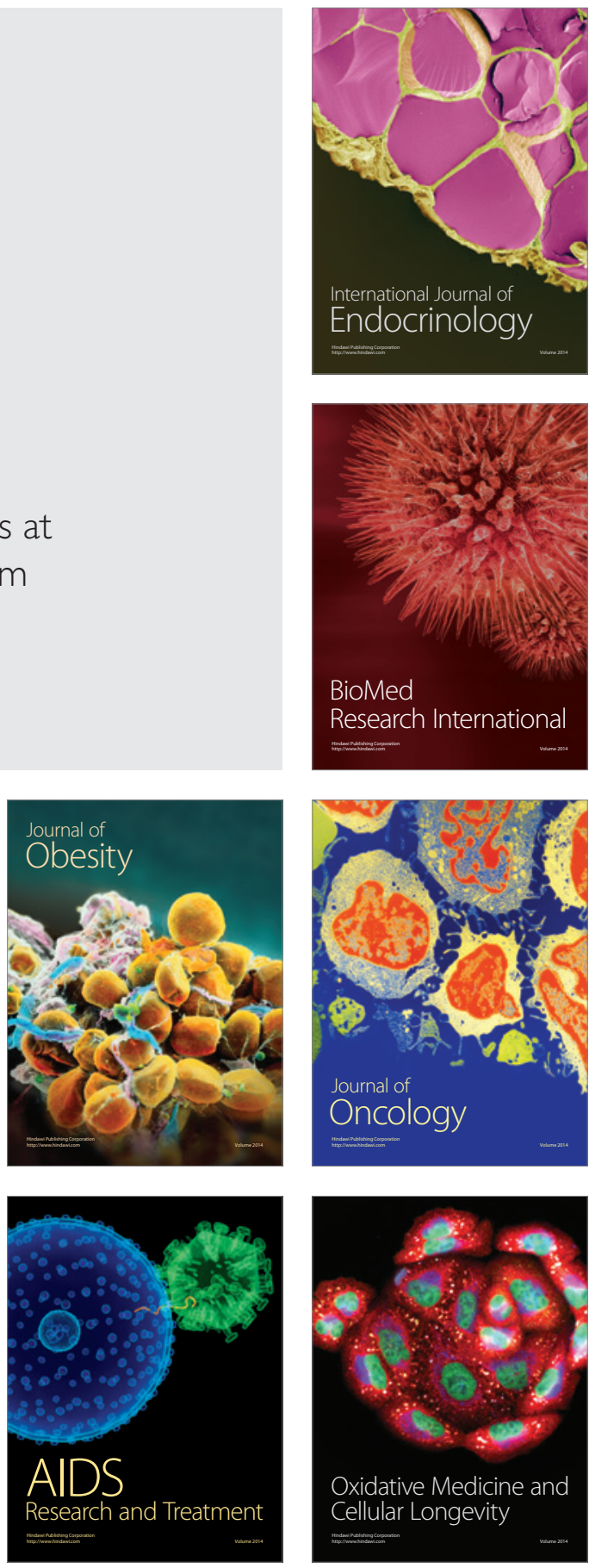